\title{
Effect of Gait Training Program with Mechanical Exoskeleton on Body Composition of Paraplegics
}

This article was published in the following Dove Press journal:

Journal of Multidisciplinary Healthcare

\section{Hyuk-Jae Choi' \\ Gyoo-Suk Kim' \\ Jung Hoon $\mathrm{Chai}^{2}$ \\ Chang-Yong $\mathrm{Ko}^{3}$}

'Department of Rehabilitation Therapy Training Research, Rehabilitation

Engineering Research Institute, Incheon, Republic of Korea; ${ }^{2}$ Department of Sports Medicine, Soonchunhyang University, Asan, Chungcheongnam-do, Republic of Korea; ${ }^{3}$ Department of Research \& Development, Refind Inc., Wonju, Gangwon-do, Republic of Korea
Correspondence: Chang-Yong Ko

Refind Inc, I, Yeonsedae-gil, Heungeopmyeon, Wonju-si, Gangwon-do 26493,

Republic of Korea

Tel/Fax +82 7048372829

Email monamicyko@gmail.com

Jung Hoon Chai

Soonchunhyang University, 22

Soonchunhyangro, Asan 31438

Chungcheongnam-do, Republic of Korea

Tel/Fax +82 1028613869

Email jhchai80@gmail.com
Purpose: To identify the effect of a 52-weeks gait training program with an exoskeletal body-powered gait orthosis on the body composition of paraplegics.

Patients and Methods: Ten subjects with spinal cord injury at the thoracolumbar spine level for more than 2 years participated and were divided into exercise $(n=5)$ and nonexercise $(n=5)$ groups. A gait training program comprising stages 1-6 with customized exoskeletal body-powered gait orthosis was conducted for 52-weeks. A six-stage gait training program was conducted to manage the body composition and prevent obesity, and the changes in the body composition before and after the program were determined through bioelectrical impedance analysis.

Results: No significant changes in weight, fat-free mass $(\mathrm{kg})$, lean body mass $(\mathrm{kg})$, and percent fat mass $(\%)$ are seen in the exercise group before and after the 52-weeks program. However, fat-free mass (pre $=47.3 \pm 6.5$, post $=44.3 \pm 5.4, \mathrm{~kg})$, lean body mass $(\mathrm{pre}=45.2 \pm 6.3$, post $=42.3 \pm 5.2, \mathrm{~kg})$, and percent fat mass (pre $=30.1 \pm 12.1$, post $=40.9 \pm 9.1, \mathrm{~kg}$ ) show significant changes $(p<0.05)$ in the nonexercise group. In the nonexercise group, among lean body mass changes over 52-weeks in the upper limbs $(-31 \%)$, trunks $(-9.7 \%)$, and lower limbs $(-8.6 \%)$, upper limbs exhibit the most significant decrease $(p<0.05)$.

Conclusion: The gait training program with exoskeletal body-powered gait orthosis has a positive effect on fat management in the whole body and lean body mass loss in paraplegics. Furthermore, it is effective in preventing continuous muscle loss and in maintaining health by reducing body fat. Body composition measurements with bioelectrical impedance analysis for paraplegics can be applied in various clinical areas and can be combined with various arbitration methods such as rehabilitation program.

Keywords: gait training, exoskeletal orthosis, lean body mass, spinal cord injury, bioelectrical impedance analysis, rehabilitation

\section{Introduction}

Spinal cord injury (SCI) patients suffer from a loss of muscle mass owing to paralysis and limited physical activity. Further, because most SCI patients have an imbalance between energy intake and energy consumption; ${ }^{1}$ they are overweight or obese. ${ }^{2}$ In the United States, more than two-thirds of all SCI patients are overweight or obese., 3 Many SCI patients also have various potentially fatal complications such as cardiovascular disease, osteoporosis, type-2 diabetes, peripheral vascular disease, osteoarthritis, bedsores, and depression. ${ }^{5,6}$

Although SCI patients need to exercise to improve their health and avoid obesity, they cannot stand up and exercise by themselves. Therefore, they perform upper body exercises including arm crank exercise, ${ }^{7,8}$ hand-bike exercise, ${ }^{9}$ and 
rowing exercise. ${ }^{10} \mathrm{SCI}$ patients perform such exercises in a sitting position. However, long-term sitting increases the risk of pressure ulcers ${ }^{11}$ and reduces smooth bowel movement. $^{12}$

To avoid these problems, standing and gait training program are used as the standard rehabilitation for SCI patients. As SCI patients cannot stand by themselves, standing and gait training program using various types of exoskeletons have been employed. ${ }^{13-16}$ In particular, exoskeletal body-powered gait orthosis (EBPGO) should be used instead of exoskeletal-powered gait orthosis (EPGO) to improve the effectiveness of exercise in SCI patients. EBPGO generally imposes a lower physiological burden than EPGO for gait exercises. ${ }^{17,18}$

Therefore, performing gait exercises using EBPGO is more effective in improving health and preventing obesity. EBPGO also affords better stability and energy efficiency than hybrid gait orthosis using functional electrostimulation. ${ }^{19}$ Existing studies on obesity have analyzed the body composition using bioelectrical impedance analysis (BIA); for SCI, the total body water (TBW, L), fat-free mass (FFM, $\mathrm{kg}$ ), and body fat mass (FM, kg) have been analyzed. ${ }^{20,21}$

Several studies have revealed that the changes in the body composition when SCI patients performed aerobic and muscle exercises, ${ }^{22}$ such as boxing, interval wheeling, arm ergometer, and rope-slam and $\mathrm{EPGO},{ }^{23}$ resulted in increased lean body mass in the upper and lower limbs and decreased fat mass. However, few studies have investigated changes in the body composition characteristics when SCI patients perform EBPGO gait exercise. In this light, in the present study, we analyze the effect of a 52weeks EBPGO gait training program on the body composition and health condition of SCI patients.

\section{Methods}

\section{Subjects}

In this study, we recruited a total of 11 subjects who had suffered an SCI in industrial accidents. Based on the preapproved RERI-IRB-200,318-2, Rehabilitation Engineering Research Institute authorized and confirmed that consent was received from all participants who were informed about the purpose of this research and that it was carried out in accordance with the Declaration of Helsinki. We selected people with paraplegia $(\mathrm{n}=11)$ who voluntarily participated in the gait training program as study subjects. Five subjects continued to participate in the gait training program for 52-weeks (EG: exercise group), whereas the other six either did not perform gait training or discontinued it in less than 4 weeks (NEG: nonexercise group). Body composition tests were performed on the study subjects before and after 52-weeks of gait training. One subject in the NEG did not participate in this test and was excluded from the results of this study. The NEG subjects did not participate in any other type of rehabilitation and exercise for 52-weeks. Table 1 provides detailed information with the Modified Ashworth Scale of affected region of the 10 subjects.

\section{Exoskeletal Body-Powered Gait Orthosis Training Program}

A 52-weeks gait training program was conducted for SCI patients who could utilize the EBPGO (Figure 1). Risk factors, such as joint contracture and spasticity which may impede standing and gait, were considered. Before starting the session, the subject's body temperature was measured to confirm signs of inflammation, infection, or fever. For preventing complications such as orthostatic hypotension

Table I Characteristics of Spinal Cord Injury Subjects

\begin{tabular}{|c|c|c|c|c|c|c|c|c|c|}
\hline & & Gender/Age & $\mathrm{Ht}$ & $\mathbf{W t}$ & Injury Level & ASIA & MAS & ADL (Ambu.) & Onset \\
\hline \multirow[t]{5}{*}{ EG } & Subl & $M / 64$ & 165 & 72 & $\mathrm{TI}$ & C & $1+$ & $\mathrm{W} / \mathrm{C}$ & 2011 \\
\hline & Sub2 & $M / 52$ & 165 & 60 & TII & A & 2 & $W / C$ & 2001 \\
\hline & Sub3 & $M / 48$ & 163 & 66 & LI & C & I & $W / C$ & 2004 \\
\hline & Sub4 & $\mathrm{F} / 54$ & 164 & 65 & LI & $A$ & I & $W / C$ & 2004 \\
\hline & Sub5 & $M / 65$ & 165 & 55 & $\mathrm{~T} 12$ & $A$ & I & $W / C$ & 2007 \\
\hline \multirow[t]{5}{*}{ NEG } & Sub6 & $M / 54$ & 168 & 72 & TII & A & $1+$ & $W / C$ & 2005 \\
\hline & Sub7 & $M / 58$ & 176 & 72 & TII & A & I & W/C & 2007 \\
\hline & Sub8 & $M / 60$ & 169 & 73 & $\mathrm{T7}$ & $A$ & 2 & $W / C$ & 2006 \\
\hline & Sub9 & $M / 52$ & 174 & 68 & TII & $A$ & I & $W / C$ & 2013 \\
\hline & Sublo & $M / 53$ & 178 & 69 & TII & $A$ & $1+$ & $W / C$ & 2004 \\
\hline
\end{tabular}

Abbreviations: EG, exercise group; NEG, nonexercise group; F, female; M, male; Ht, height (cm); Wt, weight (kg) Injury level; T, thoracic; L, lumber; ASIA, America Spinal Injury Association; A, complete; C, incomplete injury; MAS, Modified Ashworth Scale; ADL, activity daily living; Ambu., ambulation; W/C, wheelchair. 
and hypertension, we measured the subject's blood pressure and pulse before and after each session. If the body temperature of a subject exceeded $37.5{ }^{\circ} \mathrm{C}$ or abnormal signs of blood pressure and pulse appeared, the session was stopped immediately, and the subject was asked to take a break and to consult a clinical specialist.

This gait training program included stage-1 (basic standing exercises) to stage-6 (stable level of flatland walking using both Canadian elbow crutches) activities. Subjects progressed through these stages based on the decision of a skilled physiotherapist. Customized EBPGO was provided to the subjects after adaptation to the standing exercise in stage 1 . Stage 2 comprised weightbearing and weight-shifting exercises after the repeated application of a sit-to-stand exercise while wearing the EBPGO. A dynamic balance exercise with continuous walking or walking with one foot was performed by maintaining static balance within parallel bars in stages 3 and 4 . Additionally, a Canadian elbow crutch adapting exercise was applied within parallel bars. Stages 5 and 6 involved a walkway gait training program using one-sided walkers and crutches with the assistance of safety features such as harnesses and clinical specialists (physiotherapists, etc.) on the walkway (Figure 1). Considering the clinical condition of the subjects, we conducted this program two or three times a week for $\sim 120$ min per session, with the exercise intensity ranging from moderate to vigorous. ${ }^{24}$ The $120-$ min total exercise time included $30 \mathrm{~min}$ of upper and lower limb stretching before wearing the EBPGO, 30 min of balance exercise with the orthosis, and $60 \mathrm{~min}$ of standing and gait. ${ }^{25}$ The break time for each session of 120 min was applied for 10-30 minutes in consideration of the subject's clinical condition.

\section{Device for Body Composition Analysis}

The BIA device (InBody S10, Biospace Co., Ltd., Seoul) employed in this study analyzes the body composition through the impedance of the limb and body compartments
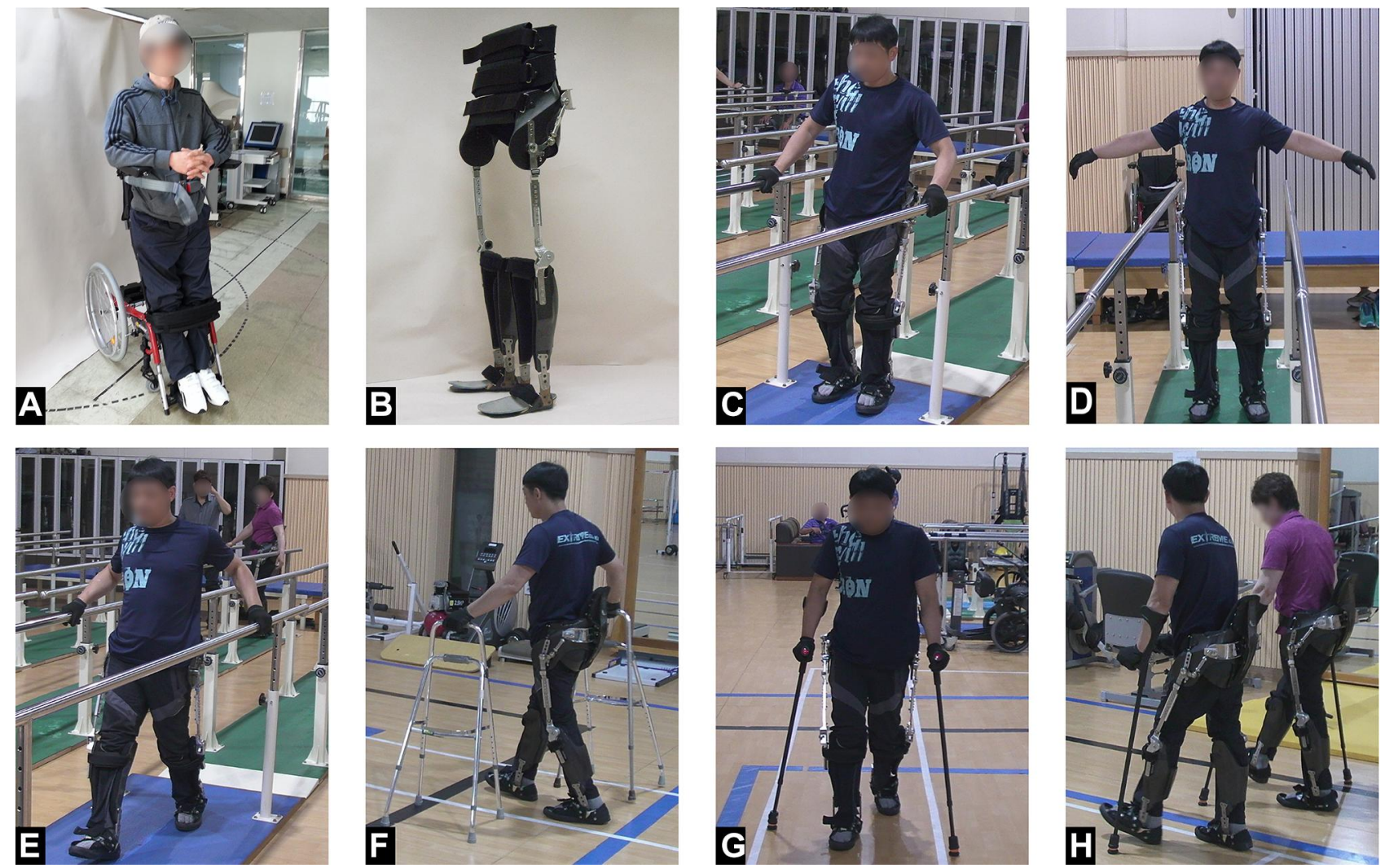

Figure I Exoskeletal body-powered gait orthosis training program. (A) Basic standing trainings in stage I. (B) Customized EBPGO was provided to the subjects after adaptation to the standing training in stage I. (C) Weight-bearing and weight-shifting trainings in parallel bars after the repeated application of a sit-to-stand training while wearing the EBPGO in stage 2. (D) A static balance training by maintaining balance without upper limbs supporting in parallel bars in stage 3 . (E) A dynamic balance training with continuous walking or walking with one foot was performed by maintaining balance with in parallel bars in stage 4 . (F) A walkway gait training program using walkers in stage 5. (G and $\mathbf{H})$ A walkway gait training program using crutches without $(\mathbf{G})$ or with $(\mathbf{H})$ the companion in stage 6 . 
using an FDA-approved multi-frequency method (1, 5, 50, 250,500 , and $1000 \mathrm{kHz}$ ). Measurements can be easily performed in a supine position for those with balance problems due to paralysis.

\section{Experimental Procedure}

The weight, height, body mass index (BMI), total body water (TBW, L), fat-free mass (FFM, $\mathrm{kg}$ ), fat mass (FM, kg), lean body mass (LBM, $\mathrm{kg}$ ), soft muscle mass (SMM, kg), and percentage body fat (PBF, \%) of the subjects were measured before conducting stage 1 of the gait training program. After 52-weeks of participating in the program, follow-up measurements were performed similarly. When performing BIA, the subjects were instructed to remove all conductive substances from the body and to completely stabilize their body in a supine position for $15 \mathrm{~min}$.

Subsequently, measurements were performed in a position where both the shoulder and the hip joints were abducted at $\sim 15^{\circ}$ with respect to the trunk for ensuring that both sides of the upper and lower limbs were not bent. Electrodes were attached to the subjects at the same locations used for persons without SCI according to the instructions of the corresponding device manufacturer. For the subjects, fluid and food intake as well as exercise before and after the test were limited, and the skin and physical condition were checked by equating the temperature and humidity from the time and measurement environment. ${ }^{26}$

\section{Data Processing and Statistical Analysis}

The body composition results were analyzed for the whole-body and segmental parts of the subjects including the upper limb (UL), lower limb (LL), and trunk (Tr). In addition, for the statistical analysis, the Mann-Whitney $U$-test was conducted as a nonparametric test for comparison between the two groups, and Wilcoxon's signed-rank test was used as a nonparametric test of the changes in the groups before and after the study using SPSS 18.0 Windows. The statistical significance level for the overall results was set to 0.05 . Data from the body measurements and BIA experiments were summarized as the mean and standard deviation. Microsoft Office Excel Ver. 2013 standard (Microsoft, USA) and SPSS 18.0 Windows Ver. (IBM, USA) were used for analyzing the results.

\section{Results}

Table 2 and Figure 2 show the changes in the whole-body composition of the subjects who underwent the 52-weeks
Table 2 Results of Whole-Body Composition

\begin{tabular}{|c|c|c|c|c|}
\hline & Group & Pre & Post & $p$-value \\
\hline Weight, kg & $\begin{array}{l}\text { EG }(n=5) \\
\text { NEG }(n=5) \\
p \text {-value }\end{array}$ & $\begin{array}{l}63.6 \pm 6.4^{\mathrm{a}} \\
71.8 \pm 7.0 \\
0.095\end{array}$ & $\begin{array}{l}63.4 \pm 7.0 \\
75.4 \pm 7.3 \\
0.111\end{array}$ & $\begin{array}{l}0.713 \\
0.052\end{array}$ \\
\hline BMI, $\mathrm{kg} / \mathrm{m}^{2}$ & $\begin{array}{l}\text { EG }(n=5) \\
\text { NEG }(n=5) \\
p \text {-value }\end{array}$ & $\begin{array}{l}23.5 \pm 2.4 \\
23.9 \pm 3.3 \\
1.000\end{array}$ & $\begin{array}{l}23.1 \pm 2.3 \\
25.3 \pm 3.2 \\
0.016\end{array}$ & $\begin{array}{l}0.034 \\
\mathbf{0 . 0 4 0}\end{array}$ \\
\hline TBW, L & $\begin{array}{l}\text { EG }(n=5) \\
\text { NEG }(n=5) \\
p \text {-value }\end{array}$ & $\begin{array}{l}30.0 \pm 3.2 \\
35.6 \pm 4.9 \\
0.056\end{array}$ & $\begin{array}{l}29.9 \pm 2.4 \\
33.3 \pm 4.1 \\
\mathbf{0 . 0 2 8}\end{array}$ & $\begin{array}{l}0.893 \\
0.022\end{array}$ \\
\hline FFM, kg & $\begin{array}{l}\text { EG }(n=5) \\
\text { NEG }(n=5) \\
p \text {-value }\end{array}$ & $\begin{array}{l}40.1 \pm 4.4 \\
47.3 \pm 6.5 \\
0.095\end{array}$ & $\begin{array}{l}39.9 \pm 3.3 \\
44.3 \pm 5.4 \\
\mathbf{0 . 0 2 8}\end{array}$ & $\begin{array}{l}0.893 \\
0.022\end{array}$ \\
\hline $\mathrm{FM}, \mathrm{kg}$ & $\begin{array}{l}\text { EG }(n=5) \\
\text { NEG }(n=5) \\
p \text {-value }\end{array}$ & $\begin{array}{l}23.5 \pm 3.5 \\
24.5 \pm 6.7 \\
1.000\end{array}$ & $\begin{array}{l}23.5 \pm 4.4 \\
31.1 \pm 8.4 \\
0.004\end{array}$ & $\begin{array}{l}0.893 \\
0.022\end{array}$ \\
\hline LBM, kg & $\begin{array}{l}\text { EG }(n=5) \\
\text { NEG }(n=5) \\
p \text {-value }\end{array}$ & $\begin{array}{l}38.2 \pm 4.1 \\
45.2 \pm 6.3 \\
0.095\end{array}$ & $\begin{array}{l}38.1 \pm 3.1 \\
42.3 \pm 5.2 \\
\mathbf{0 . 0 2 8}\end{array}$ & $\begin{array}{l}0.893 \\
0.022\end{array}$ \\
\hline SMM, kg & $\begin{array}{l}\text { EG }(n=5) \\
\text { NEG }(n=5) \\
p \text {-value }\end{array}$ & $\begin{array}{l}21.3 \pm 2.7 \\
25.3 \pm 3.9 \\
0.222\end{array}$ & $\begin{array}{l}21.2 \pm 2.1 \\
23.4 \pm 3.2 \\
\mathbf{0 . 0 2 8}\end{array}$ & $\begin{array}{l}0.786 \\
\mathbf{0 . 0 2 2}\end{array}$ \\
\hline PBF, \% & $\begin{array}{l}\mathrm{EG}(n=5) \\
\text { NEG }(n=5) \\
p \text {-value }\end{array}$ & $\begin{array}{l}36.8 \pm 3.5 \\
30.1 \pm 12.1 \\
0.151\end{array}$ & $\begin{array}{l}36.8 \pm 3.8 \\
40.9 \pm 9.1 \\
0.008\end{array}$ & $\begin{array}{l}0.892 \\
0.022\end{array}$ \\
\hline
\end{tabular}

Notes: ${ }^{2}$ Mean \pm standard deviation; Bold values indicate $p<0.05$.

Abbreviations: EG, exercise group; NEG, nonexercise group; BMI, body mass index; TBW, total body water; FFM, fat-free mass; FM, fat mass; LBM, lean body mass; SMM, skeletal muscle mass; PBF, percent body fat.

gait training program. Before participating in the program, there were no significant differences in the weight, TBW (L), FFM (kg), FM (kg), LBM (kg), SMM (kg), and PBF (\%) between the EG and NEG. There were no significant changes in the weight before and after in both the EG and NEG.

In the EG, the TBW after 52-weeks was $29.9 \pm 2.4 \mathrm{~L}$, indicating a non-significant decrease from the pretest result of $30.0 \pm 3.2 \mathrm{~L}(p=0.893)$. However, after 52-weeks, the TBW $(33.3 \pm 4.1 \mathrm{~L})$ of the NEG exhibited a significant reduction from the pretest result $(35.6 \pm 4.9 \mathrm{~L})(p=0.022)$. There were no significant differences in the FFM, LBM, FM, PFM, and SMM of the EG before and after 52-weeks. In the NEG, the FFM after 52 -weeks $(44.3 \pm 5.4 \mathrm{~kg})$ was significantly reduced compared to the pretest result $(47.3 \pm 6.5 \mathrm{~kg})$ ( $p=$ $0.022)$. In addition, in the NEG, the LBM after 52-weeks $(42.3 \pm 5.2 \mathrm{~kg})$ was significantly reduced $(45.2 \pm 6.3 \mathrm{~kg})(p=$ $0.022)$. 

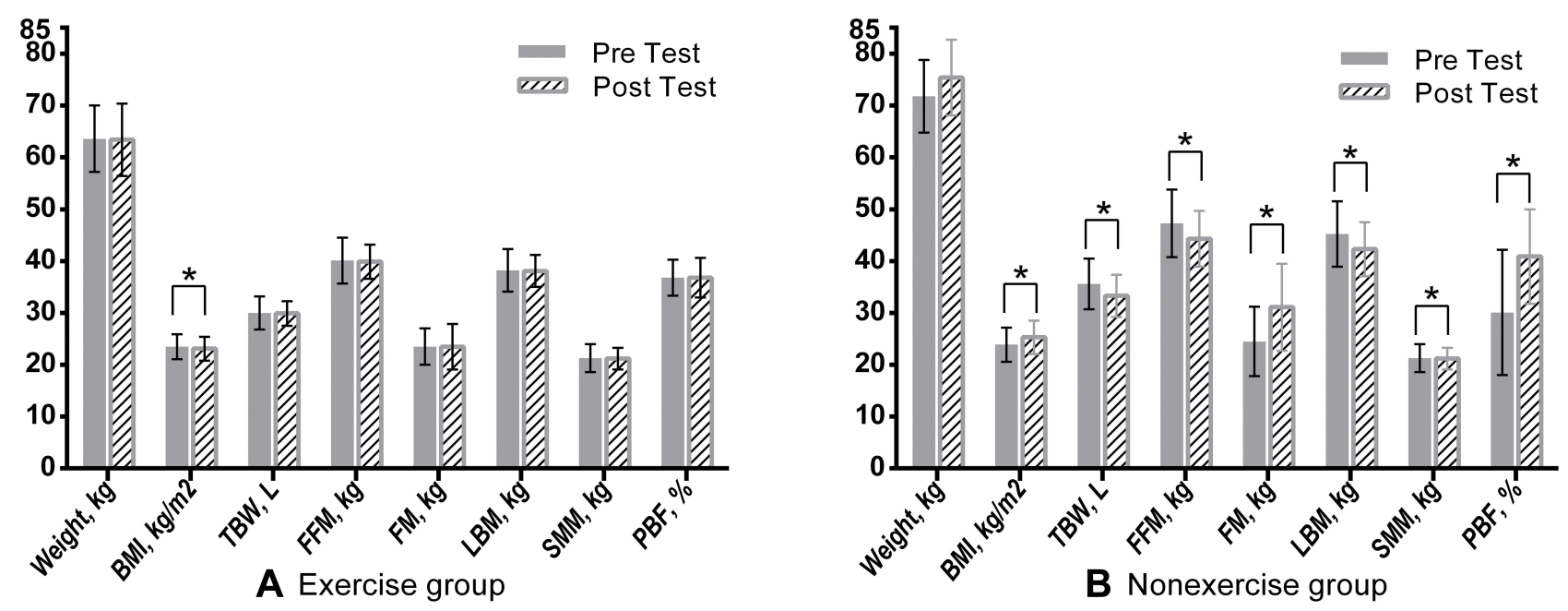

Figure 2 Change in whole-body composition between pre- and post-test. (A) Exercise group. (B) Nonexercise group. Notes: Bold values $(*)$ indicate $p<0.05$.

The FM in the NEG was $31.1 \pm 8.4 \mathrm{~kg}$ after 52 -weeks, indicating a significant increase of $5.6 \mathrm{~kg}$ from the pretest result of $24.5 \pm 6.7 \mathrm{~kg}(p=0.022)$. The PBF increased from $30.1 \pm 12.1 \%$ to $40.9 \pm 9.1 \%$ after 52 -weeks, indicating a significant increase of $10.8 \%$ ( $p=0.022$. The SMM in the NEG decreased significantly from $23.4 \pm 3.2 \mathrm{~kg}$ to 25.3 $\pm 3.9 \mathrm{~kg}$ after 52 -weeks $(p=0.022)$. There were significant differences in the TBW, FFM, FM, LBM, SMM, and PBF between the EG and NEG groups after 52-weeks $(p<0.05)$; in particular, the PBF in the NEG $(40.9 \pm 9.1 \%)$ was $4.1 \%$ higher than that in the EG $(36.8 \pm 3.8 \%)(p=0.008)$.

Table 3 lists the segmental body compositions of the upper and lower limbs and the trunk of the participants of the 52weeks gait training program. There were no significant differences in the LBM for the UL, LL, and Tr in the EG before and after 52-weeks. However, the UL_LBM $(6.9 \pm 0.8 \mathrm{~kg})$ in the
NEG after 52-weeks was significantly reduced by $3.1 \mathrm{~kg}$ compared to the pretest result $(10.0 \pm 0.9 \mathrm{~kg})(p=0.021)$.

The LL_LBM in the NEG was $18.1 \pm 3.7 \mathrm{~kg}$ after 52 weeks, showing a significant decrease of $1.7 \mathrm{~kg}$ from the pretest value of $19.8 \pm 3.4 \mathrm{~kg}(p=0.021)$. The Tr_LBM was $34.4 \pm 3.4 \mathrm{~kg}$ after 52 -weeks, exhibiting a significant decrease of $3.7 \mathrm{~kg}$ from the pretest value of $38.1 \pm 3.1 \mathrm{~kg}$ $(p=0.022)$.

To confirm the muscle loss, Figure 3 shows the relative rate of change for segmental and whole-body LBM before and after in both the EG and NEG. The wholebody LBM of the EG was maintained, but the wholebody LBM of the NEG was significantly reduced by $-6.4 \%$ after 52-weeks $(p=0.022)$. In the NEG, the reduction rate of segmental LBM was higher in the UL (31\%) than in the LL (8.6\%).

Table 3 Results of Segmental Body Composition

\begin{tabular}{|c|c|c|c|c|c|}
\hline & & Group & Pre & Post & $p$-value \\
\hline \multirow[t]{3}{*}{ LBM, kg } & Upper limb & $\begin{array}{l}\text { EG }(n=5) \\
\text { NEG }(n=5) \\
p \text {-value }\end{array}$ & $\begin{array}{l}8.6 \pm 0.4^{a} \\
10.0 \pm 0.9 \\
0.056\end{array}$ & $\begin{array}{l}9.0 \pm 0.9 \\
6.9 \pm 0.8 \\
0.690\end{array}$ & $\begin{array}{l}0.099 \\
0.021\end{array}$ \\
\hline & Lower limb & $\begin{array}{l}\text { EG }(n=5) \\
\text { NEG }(n=5) \\
p \text {-value }\end{array}$ & $\begin{array}{l}17.7 \pm 2.1 \\
19.8 \pm 3.4 \\
0.310\end{array}$ & $\begin{array}{l}17.9 \pm 2.2 \\
18.1 \pm 3.7 \\
1.000\end{array}$ & $\begin{array}{l}0.250 \\
\mathbf{0 . 0 2 1}\end{array}$ \\
\hline & Trunk & $\begin{array}{l}\text { EG }(n=5) \\
\text { NEG }(n=5) \\
p \text {-value }\end{array}$ & $\begin{array}{l}35.1 \pm 2.1 \\
38.1 \pm 3.1 \\
0.151\end{array}$ & $\begin{array}{l}36.2 \pm 3.5 \\
34.4 \pm 3.4 \\
0.421\end{array}$ & $\begin{array}{l}0.099 \\
0.022\end{array}$ \\
\hline
\end{tabular}

Notes: ${ }^{a}$ Mean \pm standard deviation; Bold values indicate $p<0.05$.

Abbreviations: EG, exercise group; NEG, nonexercise group; LBM, lean body mass. 


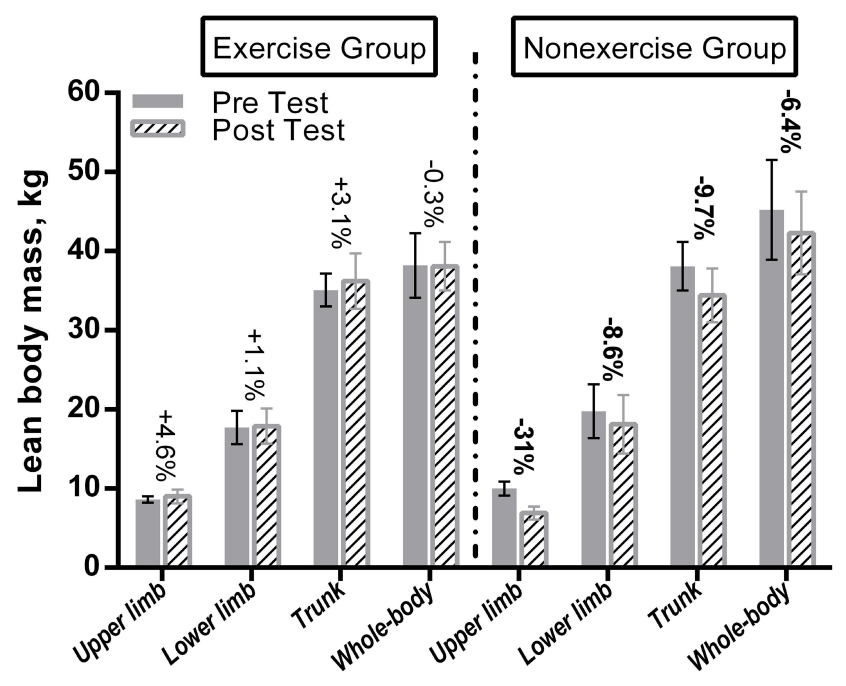

Figure 3 Change in segmental and whole-body lean body mass between pre- and post-test in exercise and nonexercise groups.

Notes:Bold values indicate $p<0.05$.

\section{Discussion}

This study was conducted to evaluate the effect of a 52weeks training program with EBPGO in preventing obesity in SCI patients through body composition analysis. The EBPGO applied in this study has the function to act through voluntary movements of the subject; however, previous studies were conducted through assist-as-needed control $^{27}$ and were powered by pneumatic muscle actuator scheme $^{28}$ on robotic orthosis and treadmill. The subject's ability to use muscle and activity is needed for EBPGO; however, in previous studies ${ }^{27,28}$ that used robotic orthosis, the subject's movement was restricted owing to the powered assistant input trajectory in the treadmill, and thus it was difficult to actively use it for maintenance and enhancement of muscle function.

Therefore, this study was conducted by applying exoskeletal orthosis including body-powered method to induce voluntary muscle contraction and prevent muscle loss during gait.

There were no significant differences in the LBM, FM, and PFM of the EG before and after the 52-weeks training program in this study. These results differ from those of a study conducted by Giangregorio et al, ${ }^{29}$ in which SCI patients $(n=5)$ performed body-weight-supported treadmill training (BWSTT) for 20 weeks; the results showed an increase $(n=3)$, decrease $(n=1)$, and no change $(n=1)$ in the whole-body LBM among the subjects. The FM increased in the whole-body for four among the five participants. The muscle cross-sectional area in the lower limbs and FM increased in all subjects $(\mathrm{n}=5)$.
However, the results of this study are similar to those of the study conducted by Giangregorio et $\mathrm{al}^{30}$ for 52 weeks on SCI patients $(\mathrm{n}=13)$.

The whole-body LBM $(47.8 \pm 8.9 \mathrm{~kg})$ after 52 -weeks (=144 sessions) of weight support motion showed a significant increased difference of $4.4 \%$ compared to the pretest value $(45.9 \pm 8.7 \mathrm{~kg})(p=0.003)$. In addition, no significant results were observed, although the post-test FM $(24.0 \pm 10.6 \mathrm{~kg})$ increased by $5.1 \%$ from the pretest value $(23.6$ $\pm 11.0 \mathrm{~kg}$ ). These differences may be attributed to the training duration ( 20 weeks in the 2005 study by Giangregorio et al vs 52-weeks in the 2006 study by Giangregorio et al and the present study) rather than to the type of gait training (BWSTT: two existing studies vs gait training using body-powered gait orthosis in the present study).

The positive effects of gait training for body composition in this study are similar to those of the study conducted by Giangregorio et $\mathrm{al}^{30}$ for 52 -weeks on SCI patients. Nevertheless, there were differences between our study, and the study conducted by Giangregorio et al Chisholm et $\mathrm{al}^{31}$ reported more advantages of the overground exercise for SCI patients in aspect of postural stability related to daily function activity as compared to the treadmill-based exercise. The subjects in the study of Giangregorio et $\mathrm{al}^{30}$ performed the treadmill-based exercise, whereas the subjects in our study performed the overground exercise. Additionally, in the previous study, there was a limit to the measurement of fat and lean mass in the whole-body ${ }^{29,30}$; however, we measured wholebody and segmental body composition through BIA device including the UL, LL, and Tr.

In addition, differences in the time of occurrence of SCI may influence the results because FM generally increases in SCI patients over the injury period. ${ }^{1,32}$ However, the effect is not significant as there were no differences with respect to the study conducted by Giangregorio et al. ${ }^{30}$ This may indicate that sufficient and sustained stimulation has a major impact on the FM. Meanwhile, considering the differences from the study by Giangregorio et al, ${ }^{29}$ the type of exercise and time of occurrence of SCI may also affect the results if the exercise period is small. However, further studies are needed to evaluate this.

In the NEG, the LBM changes in the body parts exhibited a significant decrease in the following order: UL $(-31 \%), \operatorname{Tr}(-9.7 \%)$, LL $(-8.6 \%)$, and whole-body $(-6.4 \%)$. These results indicate that muscle loss in the whole-body as well as limbs and trunk can occur after 
SCI. By contrast, the EG did not show muscle loss in any area. This demonstrates that the EBPGO training program affects not only the LL but also the UL and whole-body. These results indicate the need for both UL coordination and UL-oriented physical supporting capabilities because the 52-weeks training program comprises balancing and weight-shifting exercises for gait and standing.

Mekki et $\mathrm{al}^{33}$ reported that exoskeletal-powered robotic orthosis can change the metabolism by increasing the whole-body muscle mass and decreasing whole-body FM and PFM where sufficient training stimulus is given to the user of robotic orthosis.

There were no significant differences in the weight $(\mathrm{kg})$ of the EG during the training program of 52-weeks in this study. These results differ from those of a study conducted by Karelis et al, $^{23}$ in which SCI patients $(n=5)$ performed EPGO training using the Ekso for 6 weeks; the results showed an increase $(n=5)$ in the whole-body weight.

These differences may be attributed to the sufficient training stimulus through voluntary muscle contraction (power assist in the 2017 study by Karelis et al vs nonpower assist in the present study). Therefore, with the EBPGO training program including sufficient stimulus, a positive effect could be observed on the muscle loss as well as on the management of the whole and segmental body fat for SCI patients. Although several research studies $^{34,35}$ on upper and lower extremity rehabilitation using various exoskeletal-powered devices have been conducted, comparative studies are needed to analyze the advantages of rehabilitation exercises through power and control algorithms to improve the metabolism of SCI patients in future research.

\section{Study Limitations}

In this study, the number of the subjects in each group was small. Therefore, the statistical power might not be sufficient. Additionally, the type of exercise and time of SCI incidence as well as the exercise period should be considered as one of the main factors to affect the effects of exercise.

\section{Conclusion}

In conclusion, the EBPGO training program was effective in preventing continuous muscle loss in SCI patients and in reducing body fat to maintain health. Moreover, it is necessary to compare the effect of gait exercise between powered gait orthosis and body-powered gait orthosis.

\section{Acknowledgments}

This work was supported by the Technology Innovation Program [or Industrial Strategic Technology Development Program (20003914)] and was funded by the Ministry of Trade, Industry and Energy (MOTIE, South Korea). CoCorrespondence: Jung Hoon Chai and Chang-Yong Ko.

\section{Disclosure}

Chang-Yong Ko is an employee of Refind Inc. The authors report no other potential conflicts of interest for this work.

\section{References}

1. Sedlock DA, Laventure SJ. Body composition and resting energy expenditure in long term spinal cord injury. Paraplegia. 1990;28 (7):448-454. doi:10.1038/sc. 1990.60

2. Gorgey AS, Caudill C, Sistrun S, et al. Frequency of dietary recalls, nutritional assessment, and body composition assessment in men with chronic spinal cord injury. Arch Phys Med Rehabil. 2015;96 (9):1646-1653. doi:10.1016/j.apmr.2015.05.013

3. Gorgey AS, Gater DR. Prevalence of obesity after spinal cord injury. Top Spinal Cord Inj Rehabil. 2007;12(4):1-7. doi:10.1310/sci1204-1

4. Rajan S, McNeely MJ, Warms C, Goldstein B. Clinical assessment and management of obesity in individuals with spinal cord injury: a review. J Spinal Cord Med. 2008;31(4):361-372. doi:10.1080/ 10790268.2008.11760738

5. Garshick E, Kelley A, Cohen SA, et al. A prospective assessment of mortality in chronic spinal cord injury. Spinal Cord. 2005;43 (7):408-416. doi:10.1038/sj.sc.3101729

6. Gater DR. Obesity after spinal cord injury. Phys Med Rehabil Clin N Am. 2007;18(2):333-51, vii. doi:10.1016/j.pmr.2007.03.004

7. de Groot PC, Hjeltnes N, Heijboer AC, Stal W, Birkeland K. Effect of training intensity on physical capacity, lipid profile and insulin sensitivity in early rehabilitation of spinal cord injured individuals. Spinal Cord. 2003;41(12):673-679. doi:10.1038/sj.sc.3101534

8. Bizzarini E, Saccavini M, Lipanje F, Magrin P, Malisan C, Zampa A. Exercise prescription in subjects with spinal cord injuries. Arch Phys Med Rehabil. 2005;86(6):1170-1175. doi:10.1016/j.apmr.2004.11.014

9. de Groot S, Kouwijzer I, Baauw M, Broeksteeg R, Valent LJ. Effect of self-guided training for the HandbikeBattle on body composition in people with spinal cord injury. Spinal Cord Series Cases. 2018;4:79. doi:10.1038/s41394-018-0103-6

10. Wheeler GD, Andrews B, Lederer R, et al. Functional electric stimulation-assisted rowing: increasing cardiovascular fitness through functional electric stimulation rowing training in persons with spinal cord injury. Arch Phys Med Rehabil. 2002;83(8):1093-1099. doi:10.1053/apmr.2002.33656

11. Park MO, Lee SH. Effects of seating education and cushion management for adaptive sitting posture in spinal cord injury: two case reports. Medicine. 2019;98(4):e14231. doi:10.1097/md.0000000000014231

12. Karimi MT. Evidence-based evaluation of physiological effects of standing and walking in individuals with spinal cord injury. Iran J Med Sci. 2011;36(4):242-253.

13. Asselin P, Knezevic S, Kornfeld S, et al. Heart rate and oxygen demand of powered exoskeleton-assisted walking in persons with paraplegia. J Rehabil Res Dev. 2015;52(2):147-158. doi:10.1682/ jrrd.2014.02.0060

14. Evans N, Hartigan C, Kandilakis C, Pharo E, Clesson I. Acute cardiorespiratory and metabolic responses during exoskeleton-assisted walking overground among persons with chronic spinal cord injury. Top Spinal Cord Inj Rehabil. 2015;21 (2):122-132. doi: $10.1310 /$ sci2102-122 
15. Miller LE, Zimmermann AK, Herbert WG. Clinical effectiveness and safety of powered exoskeleton-assisted walking in patients with spinal cord injury: systematic review with meta-analysis. Medical Devices (Auckland, NZ). 2016;9:455-466. doi:10.2147/mder. S103102

16. Yang A, Asselin P, Knezevic S, Kornfeld S, Spungen AM. Assessment of in-hospital walking velocity and level of assistance in a powered exoskeleton in persons with spinal cord injury. Top Spinal Cord Inj Rehabil. 2015;21(2):100-109. doi:10.1310/sci2102100

17. Ohta Y, Yano H, Suzuki R, Yoshida M, Kawashima N, Nakazawa K. A two-degree-of-freedom motor-powered gait orthosis for spinal cord injury patients. Proc Inst Mech Eng H. 2007;221(6):629-639. doi:10.1243/09544119jeim55

18. Tanabe S, Saitoh E, Hirano S, et al. Design of the Wearable Power-Assist Locomotor (WPAL) for paraplegic gait reconstruction. Disabil Rehabil Assist Technol. 2013;8(1):84-91. doi:10.3109/ 17483107.2012.688238

19. Karimi MT. Functional walking ability of paraplegic patients: comparison of functional electrical stimulation versus mechanical orthoses. Eur J Orthop Surg Traumatol. 2013;23(6):631-638. doi:10.1007/s00590-012-1049-1

20. Buchholz AC, McGillivray CF, Pencharz PB. The use of bioelectric impedance analysis to measure fluid compartments in subjects with chronic paraplegia. Arch Phys Med Rehabil. 2003;84(6):854-861. doi:10.1016/s0003-9993(02)04950-x

21. Cirnigliaro CM, La Fountaine MF, Emmons R, et al. Prediction of limb lean tissue mass from bioimpedance spectroscopy in persons with chronic spinal cord injury. J Spinal Cord Med. 2013;36 (5):443-453. doi:10.1179/2045772313y.0000000108

22. Vik LC, Lannem AM, Rak BM, Stensrud T. Health status of regularly physically active persons with spinal cord injury. Spinal Cord Series Cases. 2017;3:17099. doi:10.1038/s41394-017-0033-8

23. Karelis AD, Carvalho LP, Castillo MJ, Gagnon DH, AubertinLeheudre M. Effect on body composition and bone mineral density of walking with a robotic exoskeleton in adults with chronic spinal cord injury. $J$ Rehabil Med. 2017;49(1):84-87. doi:10.2340/ 16501977-2173

24. Haskell WL, Lee IM, Pate RR, et al. Physical activity and public health: updated recommendation for adults from the American College of Sports Medicine and the American Heart Association. Med Sci Sports Exerc. 2007;39(8):1423-1434. doi:10.1249/ mss.0b013e3180616b27
25. Arazpour M, Soleimani F, Sajedi F, et al. Effect of orthotic gait training with isocentric reciprocating gait orthosis on walking in children with myelomeningocele. Top Spinal Cord Inj Rehabil. 2017;23(2):147-154. doi:10.1310/sci2302-147

26. Organ LW, Bradham GB, Gore DT, Lozier SL. Segmental bioelectrical impedance analysis: theory and application of a new technique. J Appl Physiol (Bethesda, Md: 1985). 1994;77(1):98-112. doi:10.1152/jappl.1994.77.1.98

27. Hussain S, Jamwal PK, Ghayesh MH, Xie SQ. Assist-as-needed control of an intrinsically compliant robotic gait training orthosis. IEEE Trans Ind Electron. 2017;64(2):1675-1685. doi:10.1109/ TIE.2016.2580123

28. Hussain S, Xie SQ, Jamwal PK, Parsons J. An intrinsically compliant robotic orthosis for treadmill training. Med Eng Phys. 2012;34 (10):1448-1453. doi:10.1016/j.medengphy.2012.02.003

29. Giangregorio LM, Hicks AL, Webber CE, et al. Body weight supported treadmill training in acute spinal cord injury: impact on muscle and bone. Spinal Cord. 2005;43(11):649-657. doi:10.1038/ sj.sc. 3101774

30. Giangregorio LM, Webber CE, Phillips SM, et al. Can body weight supported treadmill training increase bone mass and reverse muscle atrophy in individuals with chronic incomplete spinal cord injury? Appl Physiol Nutr Metab. 2006;31(3):283-291. doi:10.1139/h05-036

31. Chisholm AE, Alamro RA, Williams AMM, Lam T. Overground vs. treadmill-based robotic gait training to improve seated balance in people with motor-complete spinal cord injury: a case report. J Neuroeng Rehabil. 2017;14(1):27. doi:10.1186/s12984-017-0236-z

32. Kocina P. Body composition of spinal cord injured adults. Sports Med (Auckland, NZ). 1997;23(1):48-60. doi:10.2165/00007256199723010-00005

33. Mekki M, Delgado AD, Fry A, Putrino D, Huang V. Robotic rehabilitation and spinal cord injury: a narrative review. Neurotherapeutics. 2018;15(3):604-617. doi:10.1007/s13311-018-0642-3

34. Gorgey AS. Robotic exoskeletons: the current pros and cons. World J Orthop. 2018;9(9):112-119. doi:10.5312/wjo.v9.i9.112

35. Gorgey AS, Sumrell R, Goetz LL. 44 - exoskeletal assisted rehabilitation after spinal cord injury. In: Webster JB, Murphy DP, editors. Atlas of Orthoses and Assistive Devices. Fifth ed. Elsevier; 2019:440-447.e2.

\section{Publish your work in this journal}

The Journal of Multidisciplinary Healthcare is an international, peerreviewed open-access journal that aims to represent and publish research in healthcare areas delivered by practitioners of different disciplines. This includes studies and reviews conducted by multidisciplinary teams as well as research which evaluates the results or conduct of such teams or healthcare processes in general. The journal covers a very wide range of areas and welcomes submissions from practitioners at all levels, from all over the world. The manuscript management system is completely online and includes a very quick and fair peer-review system. Visit http://www.dovepress.com/testimonials. php to read real quotes from published authors. 